\title{
PERAN PERUM BULOG DALAM PEMASARAN BERAS DI KABUPATEN WAJO
}

\author{
Muhammad Imam Ma'ruf*1, Citra Ayni Kamaruddin', Maswadi², Nur Aena ${ }^{1}$ \\ ${ }^{1}$ Program Studi Ekonomi Pembangunan; Universitas Negeri Makassar \\ ${ }^{2}$ Program Studi Agribisnis; Jurusan Sosial Ekonomi Pertanian Universitas Tanjung Pura \\ e-mail: *1muhammadimammaruf@unm.ac.id
}

\begin{abstract}
The purpose of this research is to analyze the marketing margin of rice that generated by farmers on Belawa, Wajo Regency, South Sulawesi Province. This research used crosssection data based on the time dimension. This research used snowball sampling to determine the sample. There are 25 people as respondent sample. This study used in-depth interview method, and analysis tools such as marketing's margin function, classic assumption test, $F$ test, and t-test. Public Corporation Logistics Agency (Bulog) acts as a provider of rice in the form of realization to meet food. Bulog is expected to control the supply and distribution of grain and rice in region IV of Wajo sub-division. There are four grain/rice marketing channels on Belawa, Wajo Regency, South Sulawesi Province. Bulog has not played a sufficient role in the grain/rice marketing channel on Belawa, Wajo Regency, South Sulawesi Province; even though the highest marketing margin is Rp 4,167/kg with a 52.75\% farmer share.
\end{abstract}

Keywords: Bulog, Marketing, Rice.

\section{PENDAHULUAN}

Sulawesi Selatan dikenal sebagai salah satu daerah penghasil padi terbesar di kawasan Indonesia timur dan merupakan sentra produksi beras urutan keempat di Indonesia serta paling besar di Pulau Sulawesi dengan lahan sawah seluas 649.190 ha yang terdiri dari sawah irigasi seluas 390.768 ha dan non-irigasi seluas 258.422 ha (Badan Pusat Statistik, 2017). Sektor pertanian tidak lepas dari fungsi utamanya sebagai sumber penyediaan bahan pangan. Jumlah konsumsi masyarakat yang tiap tahunnya semakin meningkat disebabkan karena jumlah penduduk yang semakin meningkat.

Pangan merupakan kebutuhan dasar utama bagi manusia yang harus dipenuhi setiap saat. Menurut UU No.7 Tahun 1996 tentang pangan, sebagai kebutuhan dasar dan salah satu hak asasi manusia, pangan mempunyai arti dan peran yang sangat penting bagi kehidupan suatu bangsa. Ketersediaan pangan yang lebih kecil dibandingkan kebutuhannya dapat menciptakan ketidakstabilan ekonomi. Kondisi pangan yang kritis bahkan dapat membahayakan stabilitas ekonomi dan stabilitas nasional (Bulog, 2018). Ketersediaan pangan untuk memenuhi kebutuhan pangan diupayakan melalui produksi dalam negeri termasuk cadangan pangan. Impor pangan merupakan pilihan terakhir jika terjadi kelangkaan produksi pangan (Lantarsih, 2016).

Kinerja Bulog di era sebelum menjadi Perum bertolak belakang dengan perkembangan kinerja Bulog setelahnya. Hal ini dapat dilihat dari tingkat produktivitas pangan yang cenderung fluktuatif. Beberapa pendapat mengungkapkan hal ini karena imbas dari kesepakatan dengan World Trade Organisation (WTO) yang dicirikan dengan (1) 
pengurangan total atas berbagai subsidi yang dianggap mendistorsi perdagangan; dan (2) jumlah subsidi ekspor dikurangi hingga 21 persen dari tiap produk. Kesepakatan ini berimbas pada sektor pertanian, sehingga berbagai subsidi seperti pupuk dipangkas signifikan. Dampak yang paling dirasakan adalah laju impor komoditas strategis(Nasution, 2016). Marjin pemasaran adalah seluruh biaya pemasaran yang dikeluarkan oleh pelaku tataniaga (marketing cost) dan keuntungan yang diterima pelaku tataniaga (marketing profit) mulai dari pintu gerbang produsen ke konsumen akhir (Haryani \& Mulyaqin, 2013). Untuk mengatur tata niaga komoditas pangan perlu untuk pembinaan dan bantuan pemberdayaan kelompok tani serta pembangunan sistem informasi produksi dan pasar serta Perda tentang tata niaga komoditas pangan untuk menjaga stabilitas harga (Riyadh, 2018).

Tugas publik Perum Bulog merupakan amanat dari Inpres No. 3 Tahun 2012 tentang kebijakan Pengadaan Gabah/Beras dan Penyaluran Beras oleh Pemerintah, yang merupakan pengejawantahan intervensi pemerintah dalam perberasan nasional untuk memperkuat ketahanan pangan. Ketiga tugas publik Bulog tersebut saling terkait dan memperkuat satu sama lain sehingga dapat mewujudkan ketahanan pangan rumah tangga maupun nasioanal yang lebih kokoh (Bulog, 2019). Ketiga tugas publik tersebut adalah pertama, melaksanakan kebijakan pembelian gabah/beras dalam negeri dengan ketentuan Harga Pembelian Pemerintah (HPP). Kegiatan ini diwujudkan dalam bentuk pengadaan gabah dan beras dalam negeri oleh Perum Bulog. Tugas kedua, menyediakan dan menyalurkan beras bersubsidi bagi kelompok masyarakat berpendapatan rendah yang diwujudkan dalam pelaksanaan program RASKIN. Sedangkan tugas ketiga, menyediakan dan menyalurkan beras untuk menjaga stabilitas harga beras, menanggulangi keadaan darurat, bencana, dan rawan pangan. Kegiatan ketiga dilaksanakan dalam bentuk pengelolaan Cadangan Beras Pemerintah (CBP). Perkembangan realisasi pengadaan beras oleh Perum Bulog Wajo tahun 2012-2016 dapat dilihat pada Tabel 1.

Tabel 1. Realisasi Pengadaan Beras Perum Bulog Subdivre Wilayah IV Kabupaten Wajo Tahun 2016

\begin{tabular}{cc}
\hline Tahun & Banyaknya $(\mathrm{kg})$ \\
\hline 2012 & 32.218 .020 \\
2013 & 24.968 .800 \\
2014 & 21.745 .065 \\
2015 & 22.208 .125 \\
2016 & 27.938 .165 \\
\hline
\end{tabular}

Sumber: Badan Pusat Statistik Kabupaten Wajo, 2017

Tabel 1 menunjukkan bahwa di Kabupaten Wajo Perum Bulog mengadakan realisasi beras kepada masyarakat sesuai dengan kebijakan pemerintah. Realisasi pengadaan beras mengalami fluktuasi selama lima tahun terakhir. Hal ini dapat memenuhi kebutuhan pangan secara menyeluruh dan siap menampung semua output (beras) di wilayah IV Subdivre Wajo.

Beberapa faktor yang diidentifikasi sebagai faktor yang menghambat dalam sistem distribusi gabah atau beras pada aspek pemasaran antara lain: (1) kualitas gabah atau beras yang dihasilkan rendah; (2) harga gabah atau beras berfluktuasi; dan (3) rendahnya proporsi 
beras yang terserap Bulog karena tidak memenuhi standar kualitas yang ditentukan (Haryani \& Mulyaqin, 2013). Untuk mengantisipasi dan menyesuaikan dengan kondisi yang telah berubah, ada berbagai pilihan dikaitkan dengan peran pemerintah dalam sistem pemasaran dengan konsekuensi atas pilihan yang diambil, akan tetapi paling tidak pilihan tersebut secara nyata bertujuan untuk meningkatkan efisiensi pasar dan juga mampu untuk mengakomodasikan kemajuan dalam pergeseran sistem pemasaran yang terjadi. Hal ini untuk meningkatkan efisiensi pemasaran, maka peran pemerintah yang menonjol adalah dalam fungsi "pembinaan". Fungsi pembinaan maka peran pemerintah antara lain dapat dilakukan dengan pengembangan kelembagaan yang diarahkan untuk peningkatan kapasitas sehingga mampu memenuhi kebutuhan masyarakat (Anantanyu, 2011).

\section{METODE PENELITIAN}

Penelitian ini bersumber dari data primer dan sekunder dengan menggunakan dimensi waktu yaitu cross-section (silang waktu) dengan jumlah sampel responden sebanyak 25 petani padi di Kecamatan Belawa Kabupaten Wajo. Lokasi penelitian dilakukan dengan teknik snowball sampling. Teknik ini merupakan teknik penggunaan sampel yang pada mulanya jumlahnya kecil, tetapi makin lama makin banyak, berhenti sampai informasi yang didapatkan dinilai telah cukup (Siregar, 2012). Jenis penelitian yang digunakan adalah metode deskriptif dan metode eksplanatori.

Untuk mengetahui faktor-faktor yang memengaruhi margin pemasaran beras yang diperoleh pada masing-masing lembaga pemasaran digunakan rumus sebagai berikut:

$$
M P=P r-P f .
$$

\section{Keterangan:}

MP: Margin pemasaran beras ( $\mathrm{Rp})$

Pr : Harga produksi beras di tingkat konsumen $(\mathrm{Rp} / \mathrm{kg})$

Pf : Harga produksi beras di tingkat produsen $(\mathrm{Rp} / \mathrm{kg})$

Untuk mengetahui faktor-faktor yang memengaruhi margin pemasaran beras digunakan dalam rumus sebagai berikut :

$$
\mathrm{MPY}=\beta_{0}+\mathrm{X}_{1}{ }^{\beta 1}+\beta_{2} \mathrm{DSP}+\delta
$$

Untuk memudahkan persamaan, maka dapat diubah menjadi linear berganda dengan metode double log atau logaritma natural (ln) sebagai berikut:

$\operatorname{lnMPY}=\ln \beta_{0}+\beta_{1} \ln X_{1}+\beta_{2} \operatorname{DSP}+\delta$

Keterangan:

MPY : Margin pemasaran produksi beras

$\beta_{0} \quad:$ Intersep/konstanta

$\beta_{1}, \beta_{2} \quad$ : Koefisien regresi

$\mathrm{X}_{1}$ : Volume pemasaran

DSP : dummy saluran pemasaran :

1, untuk saluran Perum Bulog 0, untuk saluran lainnya 
Analisis data dalam penelitian ini menggunakan uji asumsi klasik (multikolinearitas dan heterokedastisitas), ketepatan model $\mathrm{R}^{2}$ dan uji hipotesis (uji t dan uji F).

\section{HASIL DAN PEMBAHASAN}

Panjangnya saluran pemasaran akan memengaruhi besar kecilnya margin suatu produk. Semakin panjang saluran pemasaran akan semakin besar margin yang terjadi dan sebaliknya semakin pendek saluran pemasaran maka semakin kecil marginnya. Hal ini berlaku pada produk pertanian. Lembaga pemasaran memiliki posisi yang kuat dalam menentukan harga penjualan. Saluran distribusi pemasaran beras dimulai dari produsen (petani), penggilingan beras (produksi), pedagang pengumpul, sampai pada pedagang pengecer di Kecamatan Belawa dengan pola distribusi sebanyak empat saluran pemasaran dapat dilihat pada gambar 1.

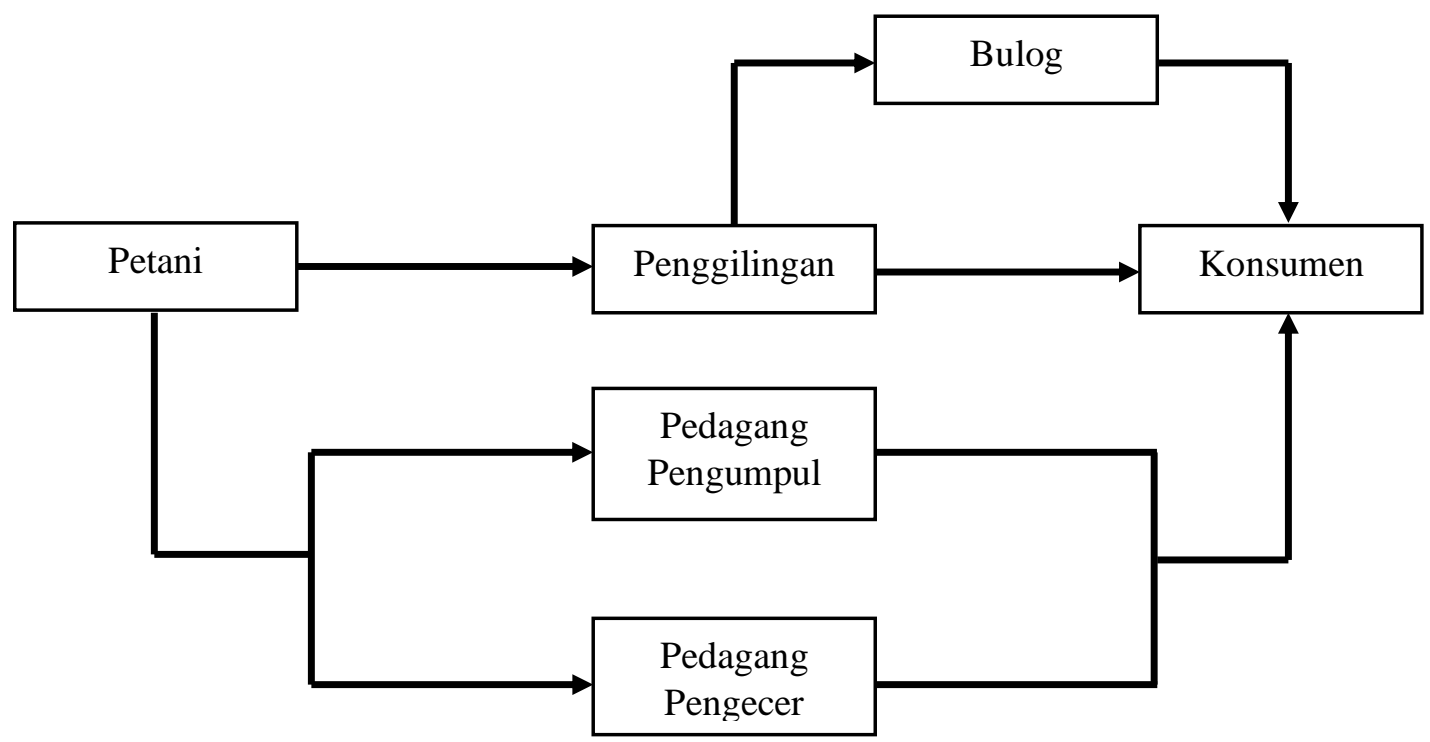

Gambar 1. Saluran Pemasaran Gabah/Beras di Kecamatan Belawa Kabupaten Wajo

Saluran pemasaran I melibatkan dua saluran pemasaran, yakni petani, penggilingan ke Bulog dan berakhir pada konsumen. Petani menjual gabah ke penggilingan lalu mengolah gabah menjadi beras. Beras kemudian dijual ke Bulog dan akhirnya akan disalurkan ke konsumen. Rincian biaya, keuntungan dan margin pemasaran pada saluran pemasaran I dapat dilihat pada Tabel 2. 
Tabel 2. Rata-rata Biaya, Keuntungan dan Margin Pemasaran Produksi Petani Padi

Pada Saluran Pemasaran I di Kecamatan Belawa Kabupaten Wajo

\begin{tabular}{|c|c|c|c|}
\hline No & Uraian & $\begin{array}{l}\text { Nilai } \\
(\mathrm{Rp} / \mathrm{kg})\end{array}$ & $\begin{array}{l}\text { Persentase } \\
\quad(\%)\end{array}$ \\
\hline \multirow[t]{2}{*}{1} & Petani & & \\
\hline & $\begin{array}{l}\text { Harga jual gabah di tingkat } \\
\text { petani }\end{array}$ & $4.652,0$ & 52,75 \\
\hline \multirow[t]{13}{*}{2} & Penggilingan & & \\
\hline & $\begin{array}{l}\text { a. Harga beli gabah } \\
\text { b. Biaya-biaya pemasaran }\end{array}$ & $5.446,6$ & 100,00 \\
\hline & Biaya listrik & 261,6 & 2,96 \\
\hline & Biaya angkut gabah & 271,6 & 3,07 \\
\hline & Biaya pengeringan & 268,0 & 3,03 \\
\hline & Biaya buruh & 272,3 & 3,08 \\
\hline & Biaya pabrik & 265,2 & 3,00 \\
\hline & Biaya operator & 233,5 & 2,64 \\
\hline & Biaya kemasan & 146,0 & 1,65 \\
\hline & Total biaya & $1.718,2$ & 19,48 \\
\hline & c. Keuntungan & $1.675,5$ & 18,99 \\
\hline & d. Margin pemasaran & $3.394,7$ & 38,49 \\
\hline & e. Harga jual beras & $8.346,7$ & 94,64 \\
\hline \multirow[t]{8}{*}{3} & Bulog & & \\
\hline & $\begin{array}{l}\text { a. Harga beli beras } \\
\text { b. Biava-biava pemasaran }\end{array}$ & $8.065,7$ & 92,97 \\
\hline & Biaya tenaga kerja & 11,0 & 0,12 \\
\hline & Biaya transportasi & 150,0 & 1,70 \\
\hline & Total biaya & 161,0 & 1,82 \\
\hline & c. Keuntungan & 311,0 & 3,52 \\
\hline & d. Margin pemasaran & 472,0 & \\
\hline & e. Harga jual beras & $8.818,7$ & 100,00 \\
\hline \multirow[t]{2}{*}{4} & Konsumen & & \\
\hline & Harga beli konsumen & $8.818,7$ & 100,00 \\
\hline \multirow[t]{4}{*}{5} & a. Total margin pemasaran & $4.166,7$ & 47,24 \\
\hline & b. Total biaya pemasaran & $1.879,2$ & 21,30 \\
\hline & c. Total keuntungan & $1.986,5$ & 22,52 \\
\hline & d. Farmer's share & & 52,75 \\
\hline
\end{tabular}

Sumber : Data Primer diolah, 2018

Pada saluran pemasaran II, konsumen langsung membeli beras dari tempat penggilingan beras yang berperan sebagai distributor beras secara langsung kepada konsumen. Rincian biaya, keuntungan dan margin pemasaran pada saluran pemasaran II dapat dilihat pada Tabel 3. 
Tabel 3. Rata-rata Biaya, Keuntungan dan Margin Pemasaran Produksi Petani Padi Pada Saluran Pemasaran II di Kecamatan Belawa Kabupaten Wajo

No Uraian Nilai $(\mathrm{Rp} / \mathrm{kg}) \quad$ Persentase $(\%)$

$1 \quad$ Petani

Harga gabah di tingkat petani $\quad 4.718,1 \quad 53,12$

2 Penggilingan

a. Harga beli gabah

$4.546,1$

53,12

b. Biaya-biaya pemasaran

Biaya listrik

136,3

1,59

Biaya angkut gabah

255,0

2,97

Biaya pengeringan

138,1

1,61

Biaya buruh

264,5

3,09

Biaya pabrik

125,0

1,46

Biaya operator

139,5

1,63

Biaya kemasan

198,0

2,31

Total biaya

$1.256,4$

14,68

c. Keuntungan

$2.755,1$

26,01

d. Margin pemasaran

$4.011,5$

46,87

e. Harga jual beras

$8.557,6$

100,00

3 Konsumen

Harga beli konsumen

$8.557,6$

100,00

4 a. Margin pemasaran

$4.011,5$

b. Farmer's share

53,12

Sumber: Data Primer diolah, 2018

Saluran pemasaran III terdiri dari petani beras, pedagang pengumpul, dan konsumen. Petani (produsen) menjual hasil produksinya kepada pedagang pengumpul kemudian menjualnya kembali ke konsumen akhir. Pada saluran ini petani menjual beras yang sebelumnya diolah di penggilingan skala kecil. rincian biaya, keuntungan dan margin pemasaran pada saluran pemasaran III dapat dilihat pada Tabel 4.

Tabel 4. Rata-rata Biaya, Keuntungan dan Margin Pemasaran Produksi Petani Padi Pada Saluran Pemasaran III di Kecamatan Belawa Kabupaten Wajo

No Uraian Nilai $(\mathrm{Rp} / \mathrm{kg}) \quad$ Persentase $(\%)$

$1 \quad$ Petani

Harga beras di tingkat

petani

2 Pedagang Pengumpul

a. Harga beli beras

b. Biaya-biaya pemasaran 


\begin{tabular}{lrr} 
Biaya angkut & 137,5 & 1,7 \\
Biaya transportasi & 125,0 & 1,55 \\
Biaya retribusi & 75,0 & 0,93 \\
Total biaya & 337,5 & 0,04 \\
c. Keuntungan & 587,5 & 7,29 \\
d. Margin pemasaran & 925,0 & 11,49 \\
e. Harga jual & $8.050,0$ & 100 \\
3 Konsumen & & 100 \\
& & \\
Harga beli konsumen & $8.050,0$ & 11,9 \\
a. Margin pemasaran & 925,0 & 88,50 \\
\hline
\end{tabular}

Sumber: Data Primer diolah, 2018

Saluran pemasaran IV terdiri dari petani, pedagang pengecer, dan konsumen. Hampir sama pada saluran pemasaran III, namun pada saluran pemasaran IV petani (produsen) menjual beras kepada pedagang pengecer lalu beras dijual konsumen akhir. Rincian biaya, keuntungan dan margin pemasaran pada saluran pemasaran IV dapat dilihat pada Tabel 5.

Tabel 5. Rata-rata Biaya, Keuntungan dan Margin Pemasaran Produksi Petani Padi Pada Saluran Pemasaran IV di Kecamatan Belawa Kabupaten Wajo

\begin{tabular}{|c|c|c|c|}
\hline No & Uraian & Nilai (Rp/kg) & $\begin{array}{c}\text { Persentase } \\
(\%)\end{array}$ \\
\hline \multirow[t]{2}{*}{1} & Petani & & \\
\hline & Harga beras di tingkat petani & 7.499 & 90,00 \\
\hline \multirow[t]{8}{*}{2} & Pedagang Pengecer & & \\
\hline & $\begin{array}{l}\text { a. Harga beli beras } \\
\text { b. Biava-biava pemasaran }\end{array}$ & 7.499 & 90,00 \\
\hline & Biaya transportasi & 116,6 & 1,39 \\
\hline & Biaya retribusi & 166,6 & 1,99 \\
\hline & Total biaya & 283,2 & 3,39 \\
\hline & c. Keuntungan & 550,1 & 6,60 \\
\hline & d. Margin pemasaran & 833,3 & 9,90 \\
\hline & e. Harga jual & $8.333,3$ & 100,00 \\
\hline \multirow[t]{2}{*}{3} & Konsumen & & \\
\hline & Harga beli konsumen & $8.333,3$ & 100,00 \\
\hline \multirow[t]{2}{*}{4} & a. Margin pemasaran & 833,3 & 9,90 \\
\hline & b. Farmer's share & & 90,00 \\
\hline
\end{tabular}

Sumber: Data Primer diolah, 2018

Hasil penelitian, Perum Bulog berperan dalam saluran pemasaran I, banyaknya beras yang dijual oleh penggilingan kepada Perum Bulog sebanyak $50.000 \mathrm{~kg}$ bahkan sampai $200.000 \mathrm{~kg}$. 
Hal ini disebabkan Perum Bulog memiliki L/C yang mampu melayani petani/penggilingan dengan membeli secara cash and carry berapapun banyaknya beras yang dijual.

Dalam penelitian ini terdapat faktor yang memengaruhi terhadap margin pemasaran beras Kecamatan Belawa Kabupaten Wajo yaitu volume pemasaran dan dummy saluran pemasaran. Dalam penelitian ini, analisis yang digunakan adalah analisis asumsi klasik dan analisis statistik dengan menggunakan variabel volume pemasaran dan saluran pemasaran. Hasil analisis dapat dilihat pada Tabel 6.

Tabel 6. Output Hasil Regresi Menggunakan Analisis Faktor-faktor yang Memengaruhi Margin Pemasaran Beras di Kecamatan Belawa Kabupaten Wajo

\begin{tabular}{|c|c|c|c|c|c|c|}
\hline & Variabel Bebas & $\begin{array}{c}\text { Tanda } \\
\text { Harapan }\end{array}$ & $\beta$ & $\mathrm{t}_{\text {hitung }}$ & Sign & VIF \\
\hline 1 & Volume Pemasaran & + & 0,838 & 8,533 & 0,000 & 1,017 \\
\hline 2 & $\begin{array}{l}\text { Dummy Saluran } \\
\text { Pemasaran }\end{array}$ & + & 0,156 & 1,585 & 0,127 & 1,017 \\
\hline & Konstanta & & & & & 5,712 \\
\hline & $F_{\text {hitung }}$ & & & & & 46,342 \\
\hline & $\mathrm{F}_{\text {tabel }}$ & & & & & 3,34 \\
\hline & $\mathrm{t}_{\text {tabel }}$ & & & & & 2,073 \\
\hline & Adjusted $\mathrm{R}^{2}$ & & & & & 0,791 \\
\hline & $\mathrm{N}$ & & & & & 25 \\
\hline
\end{tabular}

Sumber: Data Primer diolah, 2018

Keterangan:

TH : Tanda Harapan

** : Taraf signifikan dan kesalahan 0,05 atau tingkat kepercayaan $95 \%$

ns : Tidak signifikan

Sign : Nilai signifikan

VIF : Jika nilai VIF lebih kecil dari 10 maka tidak terdapat multikolinearitas, sebaliknya jika nilai VIF lebih besar dari 10 maka terjadi multikolinearitas

Dalam penelitian menggunakan taraf signifikansi 0,05 artinya taraf kepercayaannya adalah 95 persen benar dan taraf kesalahan 5 persen. Berdasarkan estimator faktor-faktor yang memengaruhi margin pemasaran hasil produksi petani padi di Kecamatan Belawa Kabupaten Wajo, bentuk dari persamaan regresi linear (multiple regression), yaitu: $\operatorname{lnMPY}=5,714+0,838 \ln \mathrm{VP}+0,156 \mathrm{DSP}+\delta$ 
Berdasarkan persamaan regresi (4), maka diubah ke dalam bentuk anti ln, yaitu:

$\mathrm{MPY}=303,08+2,312 \mathrm{VP}+0,156 \mathrm{DSP}+\delta$

Untuk mengetahui keberartian koefisien regresi maka dilakukan uji F. Adapun uji F yang dimaksud dapat dilihat pada tabel yang menunjukkan bahwa nilai $\mathrm{F}$ hitung $>\mathrm{F}$ tabel $(46,342>$ $3,34)$ dari taraf signifikansi yang digunakan dalam penelitian ini yaitu 5 persen. Dengan demikian dapat disimpulkan bahwa volume pemasaran dan dummy saluran pemasaran secara simultan berpengaruh nyata terhadap margin pemasaran beras di Kecamatan Belawa Kabupaten Wajo.

Hasil uji multikolinearitas dengan metode Variance Inflation Factor (VIF) tidak mengindikasikan tidak terjadi multikolinearitas atau kolinearitas ganda, dengan kata lain tidak ada variabel yang saling berpengaruh satu sama lain karena nilai VIF masing-masing variabel tidak melebihi dari pada 10. Pengujian heterokedastisitas dengan aplikasi SPSS menggunakan metode park test, yaitu error sebagai variabel terikat dengan cara meregresikan nilai residual dengan variabel bebas menghasilkan nilai koefisien $(\beta)$ tidak signifikan maka dapat disimpulkan tidak terdapat gejala heterokedastisitas.

Nilai konstanta sebesar 303,08 pada margin pemasaran beras menunjukkan bahwa tanpa variabel bebas (volume pemasaran dan saluran pemasaran) maka margin pemasaran beras akan meningkat sebesar Rp 303,08. Dilihat koefisien determinasi (adjusted $\mathrm{R}^{2}$ ) sebesar 0,791 berarti variansi faktor volume pemasaran dan saluran pemasaran memberikan sumbangan sebesar 79,1 persen terhadap margin pemasaran beras di Kecamatan Belawa, sedangkan sisanya 20,9 persen dipengaruhi oleh faktor lain yang tidak digunakan dalam penelitian ini.

Untuk mengetahui tingkat signifikansi antara variabel bebas (volume pemasaran dan dummy saluran pemasaran) terhadap variabel terikat (margin pemasaran) dilakukan uji t. Dari hasil pengujian yang dilakukan menunjukkan bahwa variabel bebas yaitu volume pemasaran dengan nilai t hitung sebesar 8,533 > t tabel sebesar 2,073 berarti bahwa volume pemasaran secara parsial berpengaruh positif terhadap margin pemasaran beras, sedangkan dummy saluran pemasaran I dengan nilai t hitung sebesar 1,585 < t tabel sebesar 2,073 berarti bahwa dummy saluran pemasaran I tidak berpengaruh terhadap margin pemasaran beras.

\section{KESIMPULAN DAN SARAN}

Terdapat empat saluran pemasaran gabah/beras di Kecamatan Belawa Kabupaten Wajo. Bulog belum cukup berperan pada saluran pemasaran gabah/beras di Kecamatan Belawa Kabupaten Wajo walaupun margin pemasaran tertinggi sebesar Rp 4,1667/kg dengan share petani 52,75\% . Disarankan Bulog melakukan pengembangan kerja sama yang baik agar selain mampu mempertahankan dan memperbaiki kinerja di bidang pelayanan publik terutama dalam hal penyerapan gabah dari petani. Selain itu, untuk memperkecil margin pemasaran produksi dapat dilakukan dengan memperhatikan fluktuasi harga gabah dan beras. 


\section{DAFTAR PUSTAKA}

Anantanyu, S. (2011). Kelembagaan Petani: Peran dan Strategi Pengembangan Kapasitasnya. SEPA, 7(2), 102-109.

Badan Pusat Statistik. (2017). Provinsi Sulawesi dalam angka Selatan 2015. Sulawesi Selatan: Badan Pusat Statistik.

Badan Pusat Statistik. (2017). Provinsi Sulawesi dalam angka Selatan 2016. Sulawesi Selatan: Badan Pusat Statistik.

Haryani, D, \& Mulyaqin, T. (2013). Kajian Analisis Margin Pemasaran dan Integrasi Pasar Gabah/Beras di Provinsi Banten. Buletin IKATAN, 3(1), 56-69.Lantarsih, R., Widodo, S., Darwanto, D. H., Lestari, S. B., \& Paramita, S. (2016). Sistem Ketahanan Pangan Nasional: Kontribusi Ketersediaan dan Konsumsi Energi serta Optimalisasi Distribusi Beras. Analisis Kebijakan Pertanian, 9(1), 33. https://doi.org/10.21082/akp.v9n1.2011.33-51

Nasution, L. Z. (2016). Reposisi Peran dan Fungsi Bulog dalam Tata Niaga Pangan. 59-73.

Perusahaan Umum Bulog. (2018). Ketahanan Pangan. Jakarta: Kementerian Pertanian.

Perusahaan Umum Bulog. (2019). Pangan. Jakarta: Kementerian Pertanian.

Riyadh, M. I. (2018). Analisis Saluran Pemasaran Lima Pangan Pokok dan Penting di Lima Kabupaten Sumatera Utara. Ekonomi Dan Kebijakan Publik, 9(2), 161-171.

Siregar, S. (2012). Statistika Deskriptif untuk Penelitian Dilengkapi Perhitungan Manual dan Aplikasi SPSS versi 17. Jakarta: Rajawali Pers. 